Motrivivência $\quad$ v. 26 , n. 43, p. 118-132, dezembro/2014

http://dx.doi.org/10.5007/2175-8042.2014v26n43p118

\title{
UMA NOVA CONCEPÇÃO DO CURRÍCULO NA FORMAÇÃO DE PROFESSORES DE EDUCAÇÃO FÍSICA EM SALVADOR
}

Reiner Hildebrandt Stramann ${ }^{1}$

\section{RESUMO}

O texto relata programa de intercâmbio científico-acadêmico entre pesquisadores brasileiros e alemães, com apoio do DAAD, CAPES e UFBA. Ocorrido entre 2005 e 2014, o projeto de assessoramento visou propor uma reestruturação do currículo do curso de Educação Física/Ciência do Esporte da UFBA, baseado numa perspectiva de formação em pedagogia do movimento humano, através de dez módulos de experiência-aprendizagem

Palavras-chave: Currículo modular; Pedagogia do movimento; Educação Física

1 Doutor e docente da Technische Universität Braunschweig.Braunschweig, Nidersachen /Alemanha. 


\section{INTRODUÇÃO}

O presente artigo é entendido como um relatório de pesquisa sobre um processo de assessoramento do autor alemão sobre uma reestruturação do currículo dos cursos da Ciência do Esporte na Universidade Federal de Bahia. O enfoque de assessoramento ficou no curso de Licenciatura, então na formação daqueles estudantes, que ambicionam à uma profissão numa escola brasileira. O processo de assessoramento ocorreu num prazo total de 6 anos, durante duas semanas por cada ano, entre 2005 até 2007 e, de 2009 até 2011. O projeito foi financiado pelo DAAD (Serviço Alemão de Intercâmbio Acadêmico) e a UFBA e apoiado pela CAPES. $O$ projeto mesmo é mais um exemplo do intercâmbio científico acadêmico no âmbito da Pedagogia de Movimento em geral e, da Educação Física Escolar em particular entre profissionais/pesquisadores brasileiros com profissionais/pesquisadores alemães ${ }^{2}$ (cf. KUNZ \& HILDEBRANDT-STRAMANN, 2004). O projeto teve sua continuidade de 2012 até 2014. Neste período a intenção foi preencher "o currículo novo com conteúdos, isto é, com seminários e workshops".

O assessoramento do processo de desenvolvimento de um curriculum brasileiro através de um professor alemão não é uma tarefa fácil. Tal tarefa sempre oscila entre intervenção e discrição, especialmente quando os protagonistas deste processo seguem concepções teóricas diferentes. Mas por outro lado é normal sendo um aspecto caracterísitco para processos acadêmicos, quando concepções epistemológicas embatem uma na outra. Com isso queremos expressar que o trabalho todo baseia-se numa verdadeira troca de conhecimentos de todos os participantes.

O processo de orientação inclui diferentes passos e atividades, dentre eles quatro passos principais:

1. Uma análise do currículo atual (de 2005).

2. O desenvolvimento de modelo geral da formação dos estudantes, que vão ser no futuro professores nas escolas.

3. Partindo do modelo geral tem que ser desenvolvido um modelo especial para a formação concreta.

4. Este processo de desenvolvimento de um modelo especial foi acompanhado pelos inúmeros cursos com estudantes e professores da rede escolar. Os cursos foram entendidos como exemplos teóricos e práticos de um curriculum modificado.

As tarefas dos participantes foram duas: Eles tiveram que avaliar o curso mesmo, mas também avaliar a relevância do curso para um currículum modificado. Aqui podemos observar que um processo do desenvolvimento de um currículo não acontece só na Universidade, mas também nas escolas, isto é, no lugar onde os estudantes vão trabalhar. Podemos ver também, que um processo de desenvolvimento de um currículo acontece como um processo

2 O intercâmbio entre Brasil e Alemanha começou 1980 com os professores visitantes Jürgen Dieckert e Reiner Hildebrandt-Stramann na Universidade Federal de Santa Maria. 
dialógico, com a participação daqueles que são atingidos nesta mudança.

A seguir vou apresentar o primeiro e o terceiro passo deste processo. O núcleo fica no terceiro passo, por que este passo mostra a mudança no sentido da inovação maior ${ }^{3}$.

\section{Avaliação do atual currículo ${ }^{4}$}

O atual currículo consiste em três setores essenciais:

1. Um setor de Ciência do Esporte;

2. Um setor de Didática do Esporte e,

3. Um setor da Prática do Esporte.

Analisando, com essas premissas, os conteúdos do atual currículo para a formação de professores de Educação Físca na Universidade de Salvador, constata-se que no setor da Ciência do Esporte dominam algumas disciplinas parciais de Ciência Esportiva, nas quais as disciplinas parciais de Ciências Naturais e da Teoria do Treinamento dominam claramente em números e capacidades, em relação às disciplinas parciais de Ciências Humanas. Aqui devem ser transmitidos conteúdos de conhecimento que abrangem, em primeira linha:

- O conhecimento dos princípios biológicos que controlam a estrutura acional do esforço e adaptação, ou seja, conhecimentos sobre o esforço-treino e sua reação sobre o organismo;
- O conhecimento sobre a efetividade de determinados procedimentos e formas de treino;

- O conhecimento sobre a suposta reprodução ótima de movimentos motores-esportivos, que se baseiam numa tradição cognitiva científico-natural da Ciência do Movimento.

A área didática do esporte possui dois estágios com a preparação de uma aula (didática). Aqui domina a mediação de conceitos da aprendizagem segundo o princípio de aprendizagem do mestre. A área da Prática Esportiva aprofunda essas concepções, na qual se trata, em primeira linha, da aprendizagem e treinamento de habilidades e capacidades específicas do tipo de esporte. Uma exceção constitue o curso da "capoeira".

$\mathrm{Na}$ área didática domina a concepção da "promoção do esporte" (cf. KUNZ, 2003, p. 219). Esta concepção baseia-se numa posição didática que parte do significativo fenômeno social do esporte e que vê sua tarefa sobretudo na introdução dos adolescentes no esporte institucionalizado e qualifica os alunos para a participação nas específicas ações contextuais. Para que este processo de socialização proceda possivelmente sem dificuldades, os futuros professores e professoras de Educação Física deveriam adquirir, no âmbito da formação teórica e prática do esporte, sobretudo tais conteúdos de teoria e de prática, com os quais possam, mais tarde, alcançar essa meta curricular na escola.

3 Para o fundamento do segundo passo ver Hildebrandt-Stramann (2007, pag. 26-30).

4 O palavra "atual" relaciona-se ao currículo do ano 2005. 
Resumindo, podemos avaliar o currículo tradicional por meio de:

1. Uma seperação das disciplinas de Ciência do Esporte. O que dificulta ao estudante uma visão orientada ao problema dos conteúdos e, uma compreensão sobre as conexões dos assuntos. A formação atual apresenta uma visão fragmentada da Ciência do Esporte.

2. Um domínio das disciplinas de Ciências Naturais e da Teoria do Treinamento, que representam só uma parte da Ciência do Esporte que tem, em relação à Educação Física Escolar, um baixo significado.

3. Um domínio das Ciências Naturais que tem consequências para a didática da Educação Física, em que preponderam conceitos de ensino e aprendizagem que não consideram conhecimentos atuais das disciplinas científicas da aprendizagem motora e da teoria da educação (cf. HILDEBRANDT-STRAMANN, 2001, pag. 99-110).

4. Uma prevalência de uma formação prática esportiva dos estudantes, orientada na concepção da "promoção do esporte" (cf. KUNZ, 2003, p. 219) que não considera o nível de discussão atual da Didática no Brasil.

\section{Assessoramento sobre a modificação do currículo com fundamento na Pedagogia do Movimento}

Minha proposta baseia-se em algumas pré-decisões:

1. Existe uma carga horária do curso, que não é cumprida com esta proposta. Sou da opinião, que a carga horária predeterminada significa uma sobrecarga dos estudantes, não favorecendo tempo suficiente para que estes possam estudar, treinar ou ainda preparar algo dos estudos fora do âmbito da Universidade.

2. Pretendo superar a visão fragmentada através de uma modularização do currículo. Os módulos contém seminários teóricos e práticos, que devem ser relacionados entre si.

3. Eu tento configurar um balanço do significado entre as disciplinas de Ciências Naturais e de Ciências Sociais através de um aumento do significado das Ciências Sociais.

4. A concepção didática básica dos cursos práticos são as concepções do "Ensino Aberto baseado na experiência" e da "Transformação didático-pedagógica do Esporte", duas concepções que caracterizam o paradigma da Pedagogia de Movimento (HILDEBRANDT-STRAMANN, 2001, p. 99-110; HILDEBRANDT-STRAMANN, 2010; KUNZ, 1994).

5. Para a área prática do movimento propomos substituir a orientação no tipo de esporte por "campos de experiência e aprendizagem". Isso significa temas de se movimentar abrangentes, que possibilitam uma tematização de cada campo de experiência e aprendizagem de maneira "multi-perspectivas". Com isso é incluído a tematização esportiva de cada campo de experiência e aprendizagem, mas na base de um procedimento orientado ao problema (cf. BECKMANN, HILDEBRANDT-STRAMANN \& WICHMANN, 2010, p. 31-44). 
6. A formação universitária de estudantes tem dois pontos de referência superior:

a) A Educação Física na escola;

b) O Esporte escolar, entendido como integração de movimento, jogo e esporte em toda a escola.

Para que os professores de Educação Física possam agir profissionalmente em ambas as áreas, eles necessitam das devidas qualificações e competências, que devem adquirir no âmbito da formação universitária. Resumo essas qualificações e competências com o conceito de uma "competência de ação pedagógica de movimento" (HILDEBRANDT-STRAMANN, 2007, p. 25 ff. $)^{5}$. Sob a "competência de ação pedagógica de movimento" entendemos a capacidade de poder analisar, refletir teoricamente e incenar de maneira educativa e pedagógica do movimento e da Educação Física, o Esporte escolar e o mundo da vida das crianças e adolescentes brasileiros. Por causa disso, fica necessário de maneira absoluta que um currículo contenha uma descrição das competências que os estudantes devem mostrar quando eles terminam um módulo. A seguir apresento a estrutura modularizada do curso e, um exemplo da descrição de competências ${ }^{6}$.

\section{Módulos no currículo na formação dos estudantes no curso da Licenciatura da Educação Física na UFBA}

O cerne da proposta para um "novo" currículo é a modularização do currículo em dez módulos (comp. fig. 1). Cada módulo contêm diferentes seminários com uma definida carga horária. Cada módulo tem um predeterminado valor de créditos que se forma através da soma dos créditos para cada seminário. Um módulo pode ser aprovado somente quando todos os seminários, que pertencem ao módulo, são realizados de maneira sucessível.

5 Seguindo essa determinação do conceito, durante o estudo trata-se, então, de desenvolver a competência de ação pedagógica de movimento do futuro professor de Educação Física referente a cinco dimensões de ação: a competência de 1. ação pedagógica; 2. ação de ensino; 3. ação esportiva critica; 4.ação política e 5. ação científca (cf. HILDEBRANDT-STRAMANN, 2007, p. 25).

6 O currículo modularizado aqui apresentado não conta as cargas hórarias das aulas totais e não conta também o valor dos créditos que cada módulo tem que ter. 


\begin{tabular}{|c|c|c|c|c|}
\hline $\begin{array}{l}\text { Módulo 1: } \\
\text { Movimento, escola, } \\
\text { ensino: }\end{array}$ & $\begin{array}{l}\text { Módulo 2: } \\
\text { Didática da Educação } \\
\text { Física: }\end{array}$ & $\begin{array}{l}\text { Módulo 3: } \\
\text { Campus de experiên- } \\
\text { cia e aprendizagem: }\end{array}$ & $\begin{array}{l}\text { Módulo 4: } \\
\text { Movimento e } \\
\text { educação: }\end{array}$ & $\begin{array}{l}\text { Módulo 5: } \\
\text { Movimento e } \\
\text { sociedade: }\end{array}$ \\
\hline $\begin{array}{l}\text { 1. Prática de ensino } \\
\text { 2. Estágio } \\
\text { 3. Escola móvel } \\
\text { (novo) } \\
\text { 4. Oficina de } \\
\text { movimento (novo) }\end{array}$ & $\begin{array}{l}\text { 1. Métodos de Ensino } \\
\text { 2. Medidas e Avaliação } \\
\text { 3. Análise de Ensino } \\
\text { 4. Planejamento de } \\
\text { Ensino } \\
\text { 5.Realização/Transfor- } \\
\text { mação pedagógica do } \\
\text { esporte, ligado com } \\
\text { um campo de } \\
\text { experiência e } \\
\text { aprendizagem, por } \\
\text { exemplo.: } \\
\text { - correr, saltar, } \\
\text { lançar } \\
\text { - etc. (veja módulo 3). }\end{array}$ & $\begin{array}{l}\text { 1. Ginástica } \\
\text { 2.Artes Marciais (lutar) } \\
\text { 3. Capoeira } \\
\text { 4. Jogar em equipes } \\
5 \ldots . \\
6 \ldots . \\
7 \ldots .\end{array}$ & \begin{tabular}{|l|} 
1.Teorias da \\
educação \\
2. Teorias de \\
movimentar-se \\
(novo) \\
3. Fundamentos \\
socio-filosóficos \\
de movimentar-se \\
4. Educação, \\
sociedade e \\
movimentar-se \\
5. Educação e \\
lazer \\
6. Um campo de \\
movimento \\
predeterminado \\
- Jogar em \\
Equipes ; \\
- etc.
\end{tabular} & $\begin{array}{l}\text { 1. Fundamentos } \\
\text { teóricos sociais } \\
\text { (novo) } \\
\text { 2. História da } \\
\text { Ed.Fís. } \\
\text { 3. Sociedade, Ed. } \\
\text { Fís., Esporte e Lazer } \\
\text { 4. Umm/dois } \\
\text { campo(s) de } \\
\text { movimento } \\
\text { predeterminado(s): } \\
\text { - Esporte de } \\
\text { aventura; de risco } \\
\text { - Cultura } \\
\text { urbana de } \\
\text { movimento (novo) } \\
\text { - Capoeira }\end{array}$ \\
\hline Competências & Competências & Competências & Competências & Competências \\
\hline $\begin{array}{l}\text { Módulo } 6 \\
\text { Movimento e saúde: } \\
\text { 1. Fundamentos da } \\
\text { ciência de saúde } \\
\text { 2. Educação e saúde } \\
\text { 3. Fundamentos } \\
\text { biológicos- } \\
\text { anatômicos- } \\
\text { fisiológicos } \\
\text { 4. Politicas públicas } \\
\text { de Educação, } \\
\text { Saúde, Esporte e } \\
\text { Lazer } \\
\text { 5. Um campo de } \\
\text { movimento } \\
\text { predeterminado: } \\
\text { - Movimentar-se na } \\
\text { água ou } \\
\text { - correr, saltar, } \\
\text { lançar (comp. o } \\
\text { módulo 10) } \\
\text { - etc.... } \\
6 . \text { Movimento e } \\
\text { nutrição/alimentação }\end{array}$ & $\begin{array}{l}\text { Módulo } 7 \\
\text { Movimento e } \\
\text { desenvolvimento } \\
\text { infantil/ juvenil/ } \\
\text { humano e } \\
\text { aprendizagem motora: } \\
\text { 1. Fundamentos de } \\
\text { desenvolvimento } \\
\text { infantil/ juvenil/ } \\
\text { humano e de } \\
\text { aprendizagem motora } \\
\text { 2. Um campo de } \\
\text { movimento } \\
\text { predeterminado: } \\
\text { - Ginástica } \\
\text { - etc. } \\
\text { 3. Diagnóstico do } \\
\text { movimentar-se }\end{array}$ & $\begin{array}{l}\begin{array}{l}\text { Módulo } 8 \\
\text { Abordagens métodos } \\
\text { e técnicas de } \\
\text { pesquisa: }\end{array} \\
\text { 1. Fundamentos de } \\
\text { trabalho científico } \\
\text { 2. Métodos de } \\
\text { pesquisa } \\
\text { 3. Pesquisas } \\
\text { no contexto: } \\
\text { - Movimento e Escola } \\
\text { - Ed. Fís. Escolar } \\
\text { - Movimento } \\
\text { nos âmbitos } \\
\text { extraescolares }\end{array}$ & \begin{tabular}{|l} 
Módulo 9 \\
Monografia de \\
Base
\end{tabular} & $\begin{array}{l}\text { Módulo 10 } \\
\text { Movimento e } \\
\text { treinamento: } \\
\text { 1. Fundamentos } \\
\text { teóricos da ciência } \\
\text { de treinamento } \\
\text { 2. Fundamentos } \\
\text { da Biologia, da } \\
\text { Anatomia, da } \\
\text { saúde, } \\
\text { da fisiologia. } \\
\text { 3. Treinamento e } \\
\text { Sociedade. } \\
\text { 4. Um campo de } \\
\text { movimento } \\
\text { predeterminado: } \\
\text { - correr, saltar, } \\
\text { lançar ou } \\
\text { - movimentar-se } \\
\text { na água (comp. o } \\
\text { módulo 6). }\end{array}$ \\
\hline Competências & Competências & Competências & Competências & Competências \\
\hline
\end{tabular}

Figura1: Módulos do currículo: "Novo" significa, que este seminário não existia no currículo tradicional, é um novo conteúdo do novo currículo 

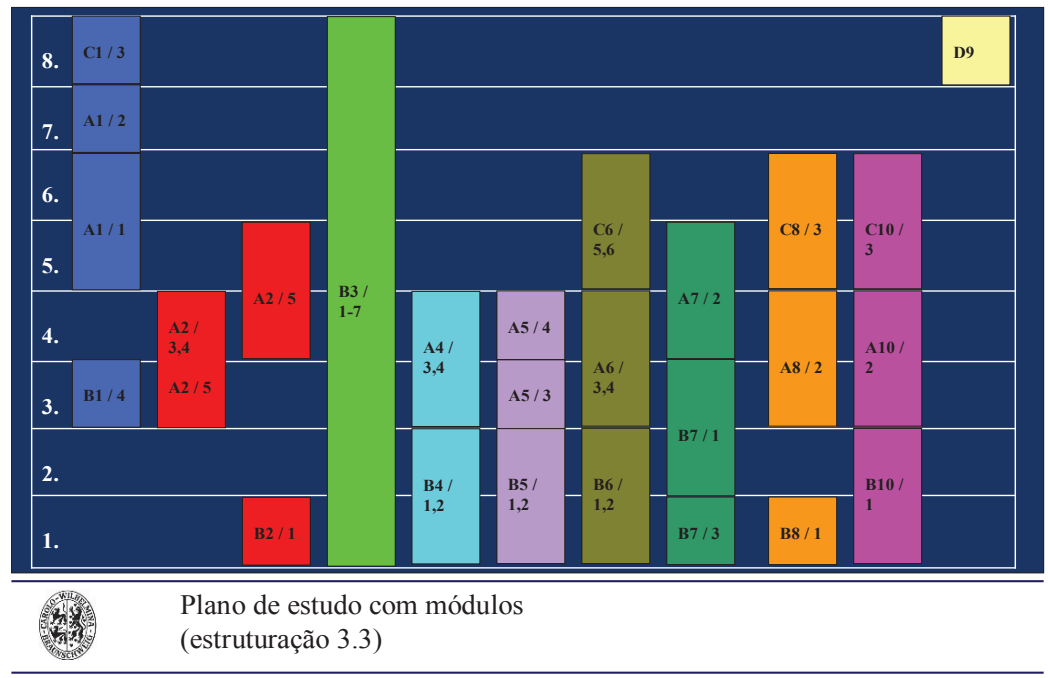

O plano de estudo demonstra a distribuição dos módulos durante o tempo de estudo. O plano parte de um tempo de estudo num total de oito semestres. Devemos ler o plano de estudo da seguinte maneira: Cada módulo tem uma cor diferente (por ex.: o módulo 1 está em vermelho). Os diferentes seminários nos módulos são numerados. Estes números aparecem no plano em combinação com um nível do seminário. Aqui é diferenciado em três nivéis: A letra "B" significa um seminário para entrar no módulo (seminário introduzido); a letra " $A$ " significa um nível mais complexo no sentido da continuação do tema do módulo, a letra " $\mathrm{C}$ " significa um seminário, onde o conhecimento dos seminários do nível " $B$ " e do " $A$ " do mesmo módulo são pressupostos; a letra "D" pertence só ao módulo 9, neste será escrito a monografia de base. Exemplo: O módulo 1 começa no terceiro semestre com o seminário 4 "oficina de movimento". O estudo neste módulo continua com a "prática do ensino" no quinto e sexto semestre (seminário nr. 1) e, no sétimo semestre com um "estágio" (seminário nr. 2). No fim dos estudos deste módulo está um seminário titulado "Escola Móvel" (nr. 3), onde os estudantes aprendem algo sobre o papel de movimento humano para a configuração de uma escola.

A seguir vou descrever o módulo 1 como um exemplo.

\section{Módulo 1: Movimento, escola, ensino}

1. Prática de ensino

2. Estágio

3. Escola móvel (novo)

4. Oficina de movimento (novo)

\section{Competências}

Neste módulo está construído o contexto entre movimento, escola e 
especificamente o ensino escolar. No início está o seminário oficina de movimento, onde os estudantes aprendem a experimentar com movimento e com o ensino de movimento (cf. BECKMANN \& HILDEBRANDT-STRAMANN, 2010, p. 45-56). A prática do ensino e o estágio podem ter o significado de um laboratório pedagógico, onde os estudantes podem treinar relações pedagógicas com crianças.

Os estudantes devem aprender neste módulo, que movimento não pode ser restringido só para o Ensino da Educação Física, mas também que movimento é uma parte immanente da configuração da Escola e do Ensino. Na teoria estas concepções são chamadas como concepções das Escolas Móveis (cf. TAFFAREL \& HILDEBRANDT-STRAMANN, 2007, p. 167-466). Numa Escola Móvel, movimento tem um papel significante na aprendizagem interdisciplinar quando por exemplo as disciplinas de Matemática, da Língua, da Filosofia ou da Fisica são combinadas com o movimento. Na teoria este tipo de aprendizagem é denominado também como "aprendizagem através de movimento". Movimento fica importante também em relação com a configuração do espaços escolares como espaços de movimento. Isso atinge a sala de ensino, os corredores até a área do pátio e o ginásio. Neste sentido a função central deste módulo é aperfeiçoar o entendimento/ a compreensão de movimento dos estudantes.

A seguir são descritas as capacidades/competências que um estudante pode adquirir nos seminários denominados "Escola Móvel" e "Oficina de Movimento".
Quais as capacidades que os estudantes de Educação Física necessitam para participar na configuração de uma Escola Móvel (cf. Hildebrandt-Stramann, 2005)?

1. Capacidade de adquirir conhecimentos através da literatura científica/ pedagógica

Para legitimar uma reforma escolar através do movimento, o professor de Educação Física necessita de conhecimentos fundamentais sobre teorias antropológicas, fenomenológicas e pedagógicas de movimento e conhecimentos sobre a relação entre movimento e aprendizagem. Estes conhecimentos ele adquire através do estudo da literatura científica na área da Educação Física, como também nas áreas acima denominadas.

\section{Capacidade de inovação ligada a um conhe-} cimento específico

Exemplo: Para uma escola móvel pertence uma "sala de aula móvel". Para construir, por exemplo móveis removivéis ou aparelhos de movimento, os estudantes devem ter a capacidade de construir uma conexão entre pensar e fazer. Pensar significa: Partindo de um conhecimento profundo da anatomia e ergonomia de sentar e sobre a configuração da organização de sentar e suas conseqüências didáticas, os estudantes têm que pensar no modo da construção de móveis que correspondam às exigências teóricas e didáticas. Além disso, necessitam da capacidade de construir os móveis (fazer). Na introdução dos móveis na aula, compete aos estudantes/os professores a capacidade didática de relacionar esta introdução com temas do corpo e da postura (a capacidade da transformação didática). No plano de formação, isso é considerado nas disciplinas chamadas "Oficina de Movimento". Ligada a esta está a Oficina 
de Pesquisa, onde os estudantes aprendem métodos de avaliação.

\section{Capacidade de cooperação}

Tanto a aprendizagem interdisciplinar, quanto o desenvolvimento de um programa escolar são caracterizados pela necessidade de cooperação entre os professores das diferentes áreas. Isso diz respeito à cooperação dos professores de Educação Física entre sí, como também à cooperação desses com os professores de outras disciplinas e de outras áreas de aprendizagem. Os professores de Educação Física devem procurar superar seu isolamento, causado muitas vezes por eles mesmos, e procurar uma participação ativa num consenso abrangente de Educação.

\section{Capacidade de avaliação}

Processos de inovação têm que ser avaliados. São necessárias informações sobre o efeito das inovações, se foi alcançado o que se imaginou. Para isto é necessário formular claramente as expectativas, ou seja o problema, constatar o estado atual e escolher métodos correspondentes através dos quais se obtém conhecimentos sobre o processo. É de considerar, que tais processos de avaliação devem ser realizados como processos autônomos de avaliação, baseados no conceito teórico da pesquisa-ação (cf. Altrichter \& Posch 1994). Neste aspecto existe também uma ligação com o módulo nr. 8.

Quais capacidades os estudantes de Educação Física podem ganhar num seminário "Oficina de Movimento"?

\section{Capacidade de experimentar}

Alunos, estudantes e professores de Educação Física experimentam com o movimento nas situações de movimento auto-construídas.

\section{Capacidade de construir}

Alunos, estudantes e professores de Educação Física inventam aparelhos e materiais de movimento e os constroem.

\section{Capacidade de ensinar e cooperar}

Para os alunos, estudantes e professores da Educação Física a oficina de movimento pode ter a função de um lugar de aprendizagem didática ou uma instituição de aperfeiçoamento profissional na área da didática. A oficina de movimento assume estas funções, quando os professores e estudantes têm a possibilidade de experimentar com a encenação de ensino e com diferentes tipos de aprendizagem. Um exemplo para professores podem ser aulas livres durante o dia escolar, onde eles têm a possibilidade de observar os alunos e planejar junto com colegas projetos comuns etc. Para os estudantes a prática com crianças pode ter o significado de um laboratório pedagógico, onde podem treinar relações pedagógicas com crianças. Numa dessas oficinas de movimento, os estudantes devem ter a possibilidade de aprender de maneira diferente, isto é, ativa, pesquisando, descobrindo, criativo, aberto. Os futuros professores devem aprender esta atitude com a intenção de ensinar na escola, nas aulas de Educação Física, desta maneira (capacidade de ensinar e cooperar).

\section{Capacidade de refletir teoricamente}

Alunos, estudantes e professores de Educação Física refletem sobre uma oficina de movimento na base das diferentes teorias de movimento (p. ex. das teorias da fenomenológia e do Gestalt - conexão 
entre movimento e percepção), teorias de desenvolvimento infantil e adolescente, teorias didáticas como a teoria da aprendizagem aberta a experiência e teorias sociais ecológicas.

\section{Módulo 2: Campos de experiência e apren- dizagem}

A mudança mais "radical" em comparação para o currículo tradicional no curso da Licenciatura na UFBA e provavelmente em todo Brasil é a substituição das disciplinas esportivas através dos campos de experiência e aprendizagem. A estruturação da formação prática em campos de experiência e aprendizagem significa não determinar o mundo de se-movimentar desde o início para o significado esportivo. O mundo de se-movimentar contêm uma multiplicidade dos significados que podem e devem ser descobertos através dos estudantes e - nas escolas - através dos alunos. Mas isto significa também, que o significado esportivo não pode ser eliminado do ensino. $\mathrm{O}$ significado esportivo de movimento que se documenta através da competição, da comparação do rendimento e do sobrepujar do rendimento, é um significado importante, mas é um significado entre outros. Ao mesmo nível como o significado esportivo de se-movimentar são os significados expressivos, explorativos, sensitivos, comunicativos e produtivos (cf. HILDEBRANDT-STRAMANN \& FUNKE-WIENECKE, 2007, p. 59-66). Também por este motivo é importante que os procedimentos didáticos orientem-se na concepção "abertas à experiência", que é caracterizada através de um procedimento didático orientado ao problema.
Eu proponho os seguintes campos de experiência e aprendizagem:

1. Movimentar-se com e sem apareIhos (Ginástica)

2. Lutar (Artes Marciais)

3. Capoeira

4. Jogar em equipes

6. Pequenos jogos

7. Saltar, correr, lançar

8. Se-Movimentar na água

9. Se-Movimentar de maneira ritmica e dançar

10. Jogar bolas ida e volta com e sem aparelhos

11. Se-Movimentar em cima da água

12. Movimentos circences

13. etc...

Na proposta curricular decidi que os primeiros dez campos de experiência e aprendizagem são obrigatórios com cargas horárias diferentes. Por exemplo: o campo de experiência e aprendizagem "Se-Movimentar com e sem aparelhos" deveria ser estudado com uma carga horária de duas horas, mas o campo de experiência e aprendizagem "Jogar em equipes" deveria ser estudado com uma carga horária de seis até oito horas: Um seminário obrigatório, onde os jogos em equipes são tematizados de maneira interdisciplinar e mais dois seminários, onde o estudante pode optar por mais dois ou três jogos esportivos (futebol, handebol, voleibol, basquetebol, hockey etc.). Importante é que estes jogos esportivos sejam ensinados de maneira problematizadora ou genética (cf. HILDEBRANDT-STRAMANN, 2013, p. 149-168).

Além das competências especiais de cada campo de experiência e aprendizagem, 
os estudantes ganham também competências gerais neste módulo de campos de experiência e aprendizagem.

Nos campos de experiência e aprendizagem trata-se de um confronto prático e teórico com temas básicos do se-movimentar e, com isto de uma estreita ligação de teoria-prática. A isto estão ligados em primeira linha quatro objetivos:

1. Os estudantes devem ser capacitados para poder refletir teoricamente seu próprio movimentar e o de outras pessoas.

2. Os estudantes devem adquirir competências básicas de movimento e da demonstração no confronto com os temas básicos do se-movimentar. Esta capacidade só é alcançada através do movimentar ativo nas correspondentes promoções de ensino.

3. Os estudantes devem adquirir competências básicas de ensino e poder refletir teóricamente suas ações de ensino

4. Além disso, trata-se de superar as restrições habituais da teoria em metodologia e didática das disciplinas esportivas na prática do movimento da formação de professores de Educação Física e recorrer aos campos de teoria.

Ao lado destas competências gerais os estudantes ganham competências especiais em cada campo de experiência e aprendizagem. A seguir isso é esclarecido com os exemplos do campo de ginástica, aqui denominado como "movimentar-se com e sem aparelhos" e do campo de

"correr, saltar, lançar".

Competências no campo de experiência e aprendizagem "se-movimentar com e sem aparelhos"

Um seminário "se-movimentar com e sem aparelhos" é estruturado em seguintes ambitos:

\section{Manejar com aparelhos/material no sentido de adaptar-se nos aparelhos móveis}

Os estudantes devem:

- conhecer e apreender entender balançar, saltar e equilibrar como os significados principais de ginástica,

- realizar tarefas de movimentos prendadas com os temas balançar, saltar e equilibrar com o enfoque de adaptar-se nos aparelhos móveis,

- realizar tarefas de movimentos construídas de maneira autônoma com os temas balançar, saltar e equilibrar com o enfoque adaptar-se nos aparelhos móveis,

- estudar exemplos práticos apresentados na literatura e analisá-los sob os aspectos metódicos e didáticos do relacionamento entre aluno e professor, da compreensão de movimento e de ensino.

- desenvolver exemplos próprios de ensino para um dos significados e refletí-los sob os aspectos metódicos didáticos do relacionamento 
entre aluno e professor, da compreensão de movimento e de ensino.

\section{Manejar com aparelhos/material no sentido de construir situações de movimento}

Os estudantes devem:

- aprender e entender o desenvolvimento, modificação e realização das intenções de movimento através da construção das próprias situações de movimento e entender isso como um caminho metódico na ginástica escolar,

- $\quad$ apreender e entender a ação recíproca entre atividades da construção e de movimento e as possibilidades para uma aprendizagem consciente que ficam nesta ação recíproca,

- estudar exemplos práticos apresentados na literatura e analisá-los com a intenção de utilizá-los para as próprias tentativas de ensino no contexto escolar,

- desenvolver exemplos próprios de ensino e realizá-los no seminário com os estudantes ou no ensino escolar com alunos.

\section{Manejar com aparelhos/material no sentido da cooperação de ajuda e de segurança}

Os estudantes devem:

- aprender e entender que uma ajuda/ segurança são necessárias e, é uma possibilidade da formação social,

- estudar exemplos práticos apresentados na literatura e analizá-los com a intenção de utilizá-los para as próprias tentativas de ensino no contexto escolar,

- desenvolver exemplos próprios de ensino e realizá-los no seminário com os estudantes ou no ensino escolar com alunos.

\section{Competências no campo de experiência} e aprendizagem "saltar, correr, lançar" (comp. o módulo 10)

Saltar, correr e lançar são possibilidades elementares de movimento do homem e são a base de muitas disciplinas esportivas e da cultura diária de movimento e de jogo. Neste sentido as diferentes formas de correr, saltar e lançar não devem ser ensinadas somente como disciplinas esportivas de atletismo, mas sim, em suas múltiplas possibilidades para um se-movimentar orientado na saúde, em comum e também relacionada para o rendimento. Correr, saltar e lançar devem ser ensinados na formação universitária com as seguintes perspectivas:

1. Perspectivas históricas e diferentes perspectivas culturais

2. As técnicas com suas possibilidades de soluções funcionais, por exemplo para o saltar mais longe sob a consideração dos diferentes pressupostos coordinativos e condições físicas dos aprendizes.

\section{Correr, saltar e lançar sob a perspectiva histórica}

Os estudantes devem reconhecer e entender que as formas de movimento 
de correr, saltar e lançar assim como a disciplina esportiva de atletismo no seu desenvolvimento histórico tiveram diferentes sentidos e foram realizadas em diferentes tipos de movimento. A reflexão sobre estes processos históricos devem elucidar uma compreensão para os desenvolvimentos culturais e, assim para a complexidade das possiveis definições de sentido - também para atuais habilidades de movimento// movimentos técnicos (comp. Coletivo de Autores, 1992).

\section{Correr, saltar e lançar sob as diferentes perspectivas culturais}

Os estudantes devem reconhecer e entender que as formas de movimento de correr, saltar e lançar possuem nos diferentes contextos culturais diferentes definições de sentido.

\section{Correr, saltar e lançar sob a perspectiva de um movimento técnico}

Os estudantes devem reconhecer e entender que os diferentes movimentos técnicos de correr, saltar e lançar são soluções funcionais para determinados objetivos. A funcionalidade de um movimento técnico depende de um lado do objetivo (que não tem que ser automaticamente o objetivo mais rápido, mais alto, mais longe) e no outro lado dos pressupostos fisiológicos, condicionais e coordenativos .

Correr, saltar e lançar sob a perspectiva orientada ao espaço de movimento

Os estudantes devem reconhecer e entender que os diferentes movimentos técnicos de correr, saltar e lançar não são fixadas para espaços/aréas esportivas, mas sim podem ser realizados no mundo de movimento do dia-a-dia.

Correr

Os estudantes devem:

- conhecer os diferentes sentidos de correr de sentido orientado à saúde até o sentido orientado ao rendimento. Eles devem reconhecer e entender, que com os diferentes sentidos são ligados diferentes concepções de ensino e de treinamento.

- saber praticar diferentes tipos de correr (corrida de obstáculo, de diferentes distâncias etc).

- conhecer e entender que com os diferentes tipos de correr são ligados diferentes adaptações fisiológicas e com isso diferentes possibilidades de treinamento.

- devem ter a capacidade de mostrar os diferentes tipos de correr.

Saltar

Os estudantes devem:

- conhecer e praticar diferentes possibilidades de saltar (alto, longe, com diferentes varas etc.).

- conhecer e praticar diferentes concepções de ensino e de treinamento.

- devem ter a capacidade de mostrar os diferentes tipos de saltar.

Lançar

Os estudantes devem:

- saber manejar os diferentes equipamentos (aparelhos) de lançar. 
- ter a capacidade de ensinar o manejo com os diferentes equipamentos (aparelhos) de lançar.

- entender e demonstrar os diferentes princípios de acerelação dos diferentes equipamentos (apareIhos) de lançar (aceleração giratória e rectilínia).

- devem ter a capacidade de mostrar os diferentes tipos de lançar.

- devem ter a capacidade de construir diferentes aparelhos/equipamentos de lançar.

\section{CONSTATAÇÕES FINAIS}

O processo da reestruturação do currículo como um todo, com as descrições de cada módulo, de cada seminário incluindo as competências e a denominação da literatura obrigatória, realmente termina em 2014. Está aberto se este currículo ou um tipo modificado vai ser aprovado pela Universidade de Bahia e pelo Ministério. Como escrevi no início o projeito de assessoramento foi financiado pelo DAAD, mas num estreito acordo com o CAPES e CNPq. Estas instituições receberam os relatórios do processo da reestruturação e no fim o resultado. O primeiro feedback pode deixar esperar o Departamento da Educação Física da UFBA implementar este currículo ou um currículo semelhante a partir de 2015.

\section{REFERÊNCIAS}

ALTRICHTER, H. \& POSCH, P. (1994). Lehrer erforschen ihren Unterricht. Bad Heilbrunn: Klinkhard.

BECKMANN, H., HILDEBRANDTSTRAMANn, R. \& Wichmann, K. (2010).
Aprender diante de problemas. In $\mathrm{R}$. Hildebrandt-Stramann (Org.), Educação Física aberta à experiência (pag. 31-44). Rio de Janeiro: Imperial novo Milênio. BECKMANN, H. \& HILDEBRANDTSTRAMANN, R. (2010). Teoria e prática de officina de movimento. In R. HildebrandtSTRAMANN (Org.), Educação Física aberta à experiência (p. 45-56). Rio de Janeiro: Imperial novo Milênio.

Coletivo de Autores (1992). Metodologia do ensino de Educação Física. São Paulo: Cortez

FUNKE-WIENECKE, J. \& HILDEBRANDTSTRAMANN, R. (2007). Uma pedagogia de movimento orientada no desenvolvimento humano como base para a formação dos professores de Educação Física. In TAFFAREL, C. \& HILDEBRANDT; STRAMANN, R. (org.). Currículo e Educação Física (p. 59;68). Ijui/RS: Editora Unijui.

HILDEBRANDT-STRAMANN, R. (2001). Pedagogia de movimento. In: $R$. Hildebrandt-Stramann, R., textos pedagógicos sobre o ensino da educação física (p. 99-110). Ijui/ RS: Editora Unijui.

HILDEBRANDT-STRAMANN, R. (2005). Escola(s) em movimento. Movimento. Revista da Escola de Educacao Fisica da UFRGS, 11 (1), 121-142.

HILDEBRANDT-STRAMANN, R. (2007). A formação de professores de Educção Física em Salvador/BA do ponto de vista de um professor colaborador alemão. In Taffarel, C. \& Hildebrandt;Stramann, R. (org.). Currículo e Educação Física (p. 21-40). Ijui/RS: Editora Unijui.

HILDEBRANDT-STRAMANN, R. (2010). Educação Física aberta à experiência Rio de Janeiro: Imperial novo Milênio. 
HILDEBRANDT-STRAMANN, R. (2013). A necessidade de mudança metodológica no ensino da Educação Física. In: R. Hildebrandt-Stramann, R., Textos pedagógicos sobre o ensino da educação física (p. 149-168). Ijui/ RS: Editora Unijui.

KUNZ, E. (1994). Transformação Didático-

Pedagógica do Esporte. ljui/ RS: Editora Unijui.
KUNZ, E. (2003). Sportpädagogik in Brasilien - Ein Grußwort zur Emeritierung von Andreas $\mathrm{H}$. Trebels. Hamburg: Czwalina.

KUNZ, E. \& Hildebrandt-STRAMANN, R. (2004) (org.). Intercâmbios Científicos Internacionais em Educação Física. ljui/ RS: Editora Unijuí.

Taffarel, C. \& Hildebrandt-Stramann, R. (2007) (org.). Currículo e Educação

Física. Ijuí/ RS: Editora Unijui.

\title{
A NEW CURRICULUM CONCEPTION FOR THE TRAINING OF PHYSICAL EDUCATION TEACHERS IN SALVADOR-BA
}

\begin{abstract}
The paper describes the scientific and academic exchange program between Brazilian and German researchers, with support from DAAD, CAPES and UFBA. Occurred between 2005 and 2014, the advisory project aimed to propose a restructuring of the curriculum of Physical Education / Sport Science of Federal University of Bahia, based on a perspective of training in pedagogy of human movement, through ten modules of experience and learning.
\end{abstract}

Keywords: Modular Curriculum; Pedagogy of Movement; Physical Education

\section{UNA NUEVA CONCEPCIÓN DEL CURRÍCULO EN LA FORMACIÓN DE PROFESORES DE EDUCACIÓN FÍSICA EN SALVADOR-BA}

\section{RESUMEN}

El texto relata programa de intercambio científico-académico entre investigadores brasileños y alemanes, con apoyo del DAAD, CAPES e UFBA. Que ocurrió entre los años de 2005 y 2014, el proyecto de asesoramiento busco proponer una reestructuración del currículo del curso de Educación Física/Ciencia del Deporte de la UFBA, basado en una perspectiva de formación en pedagogía del movimiento humano, a través de diez módulos de experiencia-aprendizaje.

Palabras clave: Currículo Modular; Pedagogía del Movimiento; Educación Física 